\title{
Accreditation beyond 2024: A major challenge for Sri Lankan medical graduates
}

A considerable proportion of medical graduates from Sri Lankan medical schools opt to work in other parts of the world such as the UK, Canada, Australia, New Zealand, USA etc. Moreover, the majority of the postgraduate training programmes conducted by Postgraduate Institute of Medicine (PGIM), University of Colombo consist of foreign training components which require the trainee to undergo training or gain work experience for a period of 1 to 2 years in an overseas medical facility or establishment. In order to practise medicine overseas, Sri Lankan medical graduates are required to obtain registration and a license to practise with a medical practitioner-registering body in the respective country such as the General Medical Council (GMC) in the UK, the Australian Health Practitioner Regulation Agency (Ahpra) etc.

Applications for registration submitted to some of the practitioner-registering bodies in those countries are directed to the Educational Commission for Foreign Medical Graduates (ECFMG) in Philadelphia, USA for evaluation. The ECFMG acts as an accreditation agency for many medical practitioner-registering bodies globally (such as GMC, Ahpra). The Foundation for Advancement of International Medical Education and Research (FAIMER), is a non-profit foundation committed to improving world health through education and it was established by the ECFMG in the year 2000. The FAIMER creates and maintains data resources on medical education worldwide. The FAIMER together with World Federation for Medical Education (WFME) have developed and maintained the World Directory of Medical Schools.

All medical schools in Sri Lanka get routine requests from the ECFMG for clarification about their graduates whose applications are being processed by the ECFMG. Sri Lankan medical schools send details about their graduates to the ECFMG, at least few per week. The current practice of the ECFMG to recognize a medical graduate is very simple. The ECFMG considers any medical school recognized by the local practitionerregistering body of the country as a legitimate medical school. Therefore, Sri Lankan medical graduates who have obtained registration from the Sri Lanka Medical Council (SLMC) could gain registration required to practise in overseas following stipulated assessments / examinations, if any. However, in 2010, the ECFMG announced that from 2023 it will recognize graduates only from 'properly' accredited medical schools and introduced a four-phase plan for a complex mechanism for registration. Later it was differed to 2024 due to the global COVID-19 pandemic. More specifically, the ECFMG will approve graduates only from the medical schools accredited by a local or regional accrediting agency that is officially recognized by WFME. To facilitate the process, accreditation status of each medical school will be indicated in the World Directory of Medical Schools from 2021.

Currently a local accrediting agency that can be recognized by WFME, based on the newly defined criteria, is not available for Sri Lanka. None of the Sri Lankan medical schools are accredited by any foreign accrediting agency that is recognized by WFME. Therefore, graduates from Sri Lankan medical schools are unlikely to get registration to practise in other countries if the ECFMG applies its new registration criteria in the future; PGIM trainees will not be able to undergo their foreign training.

Sri Lankan medical schools need to plan for accreditation by an accrediting agency that is officially recognized by WFME. Agencies that can accredit overseas medical schools are available in some Asian counties. Therefore, Sri Lankan medical schools could apply for accreditation to such an agency and undergo a rigorous and a expensive evaluation process. The other option is to establish a local agency that could accredit medical schools in the country. Fortunately, the 
SLMC has initiated a process to create a local accrediting agency under the Council. With the establishment this new agency, each medical school will have to apply for accreditation and there will be an evaluation process according to the WFMEprescribed standards. Contributions from foreign evaluators will be required for this process. The WFME recommends a set of global standards in medical education that include 9 areas with a total of 35 subareas. These areas are defined as process, structure, contents, competencies, assessment and learning environment of medical education. Each medical faculty has to show evidence that above requirements are at an acceptable level. Some medical schools may need additional human resources and physical resources development, curriculum changes, etc. depending on the circumstances.

Some of these activities such as the establishment of a local accrediting body, evaluation of each medical school acquiring resource and other developments for a medical faculty to meet criteria for accreditation will take considerable time. The challenge is that whole process should be completed by 2024 to ensure that Sri Lankan medical graduates get ECFMG recognition in the future. If not, future medical graduates from Sri Lanka will not be able to work or obtain training in other counties.

\section{Mahinda Kommalage}

Department of Physiology, Faculty of Medicine, University of Ruhuna, Galle, Sri Lanka.

\section{Correspondence:}

Prof. Mahinda Kommalage

e-mail:mahinda1@gmail.com

Submitted on 05.01.2021 and accepted for publication on 15.03.2021

\section{References}

1. Educational Commission for Foreign Medical Graduates (ECFMG). Available from: https://www.ecfmg.org [Accessed on $15^{\text {th }}$ December 2020].

2. World Federation for Medical Education (WFME). Available from: https://wfme.org [Accessed on $15^{\text {th }}$ December 2020].

3. World Directory of Medical Schools. Available from: https://www.wdoms.org [Accessed on $15^{\text {th }}$ December 2020].

4. Foundation for Advancement of International Medical Education and Research (FAIMER).

https://www.faimer. org [Accessed on $15^{\text {th }}$ December 2020]. 